\title{
SYNANTHROPIC PLANTS AS INDICATORS OF THE ECOLOGICAL STATE OF CITY OF SAMARA
}

(C) 2016

N.V. Ivanova, candidate of biological sciences, associate professor of the Chair of Commerce, Service and Tourism Samara State University of Economics, Samara (Russia)

Abstract. This article focuses on the analysis of synanthropic flora of Samara. It surveys the history of the research of the flora of the city of Samara, and states that it is possible to base the estimation of the ecological condition of the city of Samara on the process and degree of synanthropy. When studying urbanoflorae different authors define the concept of synanthropic flora differently. O.P. Vinkovskaya, E.P. Gnatyuk, and G.S. Antipina, K.V. Kachkin, I.G. Sokolova, T.V. Astakhova, T.A.Terekhina dealt with issues of terminology. The author believes that the synantropic flora consists of adventitious cultivated plants, adventitious ruderal weeds and apofyte types.

In the conditions of the increasing anthropogenous change the process of synanthropization of the vegetable cover becomesquite urgent. The article describes the structure of the synanthropic fraction of the urban flora of Samara. The author notes that in the synanthropic fraction the share of monocotyledonous plants has considerably decreased, and that the adventitious species prevail, the flora being made up by forest-steppe boreal, nemoral and multizone plants. In the analysis of the synanthropic component of the flora such indicators as the flora synanthropy index, the adventivity index, index of the apofyteness and the index of cultivation have been calculated. The author comes to the the conclusion that synanthropy causes reduction of the flora variety.

Keywords: Samara, flora synanthropic plants, synanthropic flora, ecological state of the urban environment, urban floras, synanthropy index, adventity index, apofyteness index, cultivation index, adventitious, cultivated species, adventitious weed-ruderal species, apophytes.

УДК 57.044

\section{СОДЕРЖАНИЕ ТЯЖЁЛЫХ МЕТАЛЛОВ В ПОЧВЕННОМ ПОКРОВЕ В УСЛОВИЯХ ТЕХНОГЕНЕЗА}

(C) 2016

И.В. Казанцев, кандидат биологических наук, декан естественно-географического факультета

Т.Б. Матвеева, кандидат биологических наук, старший преподаватель кафедры биологии, экологии и методики обучения Самарский государственный соџиально-педагогический университет, Самара (Россия)

Аннотаџия. В данной статье рассматривается загрязнение почв тяжёлыми металлами в условиях техногенного воздействия. Описываются способы и пути поступления поллютантов в почвы, а также особенности их накопления в почвах, располагающихся в отводе железной дороги. Рассматривается роль придорожных лесных полос на характер распространения поллютантов. Определение содержания тяжёлых металлов в почвах осуществлялось рентгенофлуоресцентным методом. В работе представлены результаты сравнения загрязнения почв тяжелыми металлами по сравнению с кларковым значением, предельно-допустимой концентрацией, региональным фоновым уровнем. Изучение содержания тяжелых металлов проводилось на участке Куйбышевской железной дороги направления Самара-Сызрань в почвах полосы отвода, а так же в пригородных лесах и городских парках г. Самары (Ботанический сад, Загородный парк). Данные территории являются участками, подвергающимися значительному техногенному воздействию. Проведенные исследования показали, что на данных территориях наблюдается повышенное содержание ряда тяжёлых металлов в почвах, из которых основными элементами присутствующими в техногенных потоках загрязнения являются медь, никель, хром, цинк и свинец. Данный результат не противоречит стандартной экологической ситуации. Полученные материалы могут служить основой для дальнейшего мониторинга как пригородных лесов и зелёной зоны города Самары, так и транспортных сооружений.

Ключевые слова: тяжёлые металлы, поллютанты, элементный ряд накопления, предельно допустимая концентрация, региональный фоновый уровень, пригородные леса, лесополоса, экологический мониторинг, почвенный мониторинг, железная дорога, Куйбышевская железная дорога, город Самара, Самарская область.

Основной причиной ухудшения состояния урбанизированных территорий является техногенное воздействие. Самарская область является важным промышленным регионом, для которого проблема загрязнения окружающей среды является весьма актуальной. Выбросы промышленных предприятий, энергетика, сжигание отходов, минеральные удобрения, сточные воды, железнодорожный и автомобильный транспорт являются основными источниками поступления в почвенный покров загрязнителей, в том числе и целого комплекса тяжелых металлов, считающихся наиболее токсичными из поллютантов.
В сложившихся условиях все возрастающей антропогенной нагрузки на природную среду происходит резкий рост уровня её загрязнения и все большую роль в этом оказывает развитие транспортных коммуникаций и в частности железная дорога $[1,2,3,4,5]$. Их влияние на компоненты природы многоаспектно, среди которых значимым и опасным является загрязнение тяжелыми металлами. Их миграция и накопление в компонентах экосистем зависят как от ряда природных факторов, так и от интенсивности и характера техногенеза. Железнодорожная дорога является линейно сложным, системно работающим технико-технологическим 
комплексом, имеющим в своем составе путевое хозяйство, подвижной состав, ряд производств, объединенных функцией перевозки пассажиров и грузов [6].

Опасность загрязнения почв тяжелыми металлами прилегающих к железнодорожному пути опасна тем, что зачастую вблизи располагаются земли сельскохозяйственного назначения и жилые строения. Почвы в отводах железных дорог отличны от естественных по водно-физическим свойствам и химическому составу. Они переуплотнены, почвенные горизонты перемешаны с бытовыми отходами, веществами и материалами, перевозимыми по ним. Большая часть поллютантов поступает в почвы при транспортировке, вследствие рассыпания или утечки перевозимых грузов; от выхлопных газов двигателей тепловозов и отоплении вагонов углем; при истирании ходовой части и рельсов; от химического состава балластного слоя и земляного полотна; применения веществ для борьбы с сорняками, содержащих тяжелые металлы. Можно достоверно утверждать, что при эксплуатации все типы вагонов оказывают отрицательное воздействие на окружающую среду. Например, общее количество потерь при перевозках минеральных удобрений насыпью в крытых вагонах составляет до 8\%, а при перевозках в полувагонах до 28\%. При перевозках в универсальных вагонах ежегодно теряется до 7\% руды и 3\% цемента $[1,7]$.

На характер распространения тяжелых металлов в сторону от железнодорожного полотна играют роль как естественные, так и искусственные барьеры. К естественным барьерам относятся лесополосы, а к искусственным - наличие цельных ограждений. Так в ряде работ установлено, что если вблизи железнодорожного полотна находится искусственный барьер, то концентрация веществ резко возрастает перед ним и также резко снижается, практически доходя до естественного уровня за ним. Если же вблизи полотна располагается естественный барьер, то концентрация веществ резко возрастает в передовой части насаждений, но снижается более плавно по мере продвижения вглубь лесополосы. Эта зависимость возникает поскольку различные виды древесно-кустарниковых и травянистых растений обладают аккумулирующей способностью к тяжёлым металлам [8, 9, 10], но особую роль конечно же играет почва: ее тип, физико-химический состав и свойства и т.д. $[12,13,14,15,16,17,18]$. Это позволяет извлекать данные элементы из круговорота веществ, что способствует снижению уровня загрязнения окружающей среды. Пригородные леса как лесополосы так же являются подобным барьером, аккумулируя значительные количества тяжёлых металлов и существенно уменьшая их концентрацию в почвах [12]. Изучение накопления тяжелых металлов в растениях в целом имеет большое значение, как для оценки состояния растений, так и для биосферы в целом в плане понимания процессов круговорота веществ, а также для научной и практической работы по экологическому мониторингу.

Целью наших исследований явилось изучение содержания тяжёлых металлов в почвах различных районов, подвергающихся техногенному воздействию (участки Куйбышевской железной дороги, городские парки, пригородные леса г. Самары). Количественная оценка пространственного распределения тяжёлых металлов в почвах выбранных участков является важным аспектом и представляет интерес для эколого-геохимических исследований.
Изучение содержания тяжелых металлов проводилось на участке Куйбышевской железной дороги направления Самара-Сызрань в почвах полосы отвода, а так же в пригородных лесах и городских парках г. Самары (Ботанический сад, Загородный парк). Данные территории являются участками, подвергающимися значительному техногенному воздействию.

В ходе исследования были заложены пробные площади, на которых проводился отбор образцов почв по общепринятым методикам [1, 9, 19]. Почвенные пробы доводились до воздушно-сухого состояния, измельчались, просеивались через сито диаметром 1 мм, из них отбирались навески массой по 20 г и помещались в маркированные пакеты. Результаты исследования образцов были получены в дорожной экологической лаборатории Куйбышевской железной дороги. Определение содержания тяжёлых металлов в почвах осуществлялось рентген флуоресцентным методом на спектрометре М-049-П/10. Полученные значения сравнивались с нормативными данными - ПДК и региональным фоновым уровнем [20, 21, 22, 23].

При проведении количественного анализа исследуемых образцов почв на наличие тяжёлых металлов выявлено, что во всех образцах содержатся марганец, железо, медь, хром, никель, цинк, свинец, кобальт, титан, ванадий, стронций.

Марганец. Кларк марганца в почвах составляет 850 мг/кг. ПДК - 1500 мг/кг [20]. Региональный фоновый уровень для изучаемых почв - 687,7 мг/кг [13]. Средняя концентрация марганца в почвах полосы изучаемого нами участка железной дороги составляет 683,6 мг/кг. Сравнительный анализ содержания марганца в почвах полосы отвода железных дорог с региональным фоновым уровнем и ПДК показывает незначительное превышение содержания марганца в отводах железных дорог по сравнению с региональным фоновым уровнем, но не превышающим ПДК. Средняя концентрация металла в почвах городских парков соответствует 681,7 мг/кг, что практически соответствует фоновому уровню и не достигает ПДК.

Железо. Кларк железа в почвах составляет 38000 мг/кг. ПДК не определена. ОДК железа в почвах составляет 40000 мг/кг [21]. Региональный фоновый уровень - 33592 мг/кг [13]. Нами установлено, что средняя концентрация железа в полосе отвода железной дороги составляет 47354,6 мг/кг. Таким образом, содержание железа в почвах полосы отвода железных дорог превышает как ОДК, так и региональный фоновый уровень. Металл накапливается в количестве 17406,940703 мг/кг сухой почвы в парках г. Самары и 18584,731268,3 мг/кг в пригородных лесах.

Meдb. Кларк меди в почвах составляет 20 мг/кг. ПДК - 55 мг/кг [22], региональный фоновый уровень соответствует 39 мг/кг [13]. Средняя концентрация меди в почвах полосы отвода железной дороги составляет 58,2 мг/кг. Сравнивая полученные результаты с региональным фоновым уровнем и ПДК, представленные, мы пришли к выводу, что содержание меди в отводах железных дорог превышает региональный фоновый уровень и выше ПДК. Металл накапливается в количестве 48,8-101,9 мг/кг сухой почвы в городских парках и 48,7-102,8 мг/кг в почвах пригородных лесов. ПДК меди и фоновый уровень превышены на всех участках.

Хром. Кларк хрома в почвах составляет 300 мг/кг. ПДК - 100 мг/кг [23]. Региональный фоновый уровень 
- 102 мг/кг [13]. Средняя концентрация хрома в почвах изучаемой нами полосы отвода железных дорог составляет 136,4 мг/кг. Следовательно, содержание хрома в почвах полосы отвода железных дорог превышает ПДК и выше регионального фонового уровня. Концентрация металла в почвах городских парков составляет 82,9-128 мг/кг сухой почвы и пригородных лесов - 82127,5 мг/кг.

Никель. Кларк никеля в почвах составляет 40 мг/кг. ПДК составляет 85 мг/кг [23], региональный фоновый уровень - 28,6 мг/кг [13]. По результатам проведенных исследований выявлено, что никель в почвах содержится в пределах 32,4-60,6 мг/кг (пригородные леса) и 34,9-75 мг/кг (городские парки). Полученные данные свидетельствуют, что содержание металла в почвах на всех участках не достигает значения ПДК, но превышает региональный фоновый уровень примерно в 1,32,6 paзa.

Цинк. Кларк цинка в почвах составляет 50 мг/кг. ПДК - 100 мг/кг [23]. Региональный фоновый уровень - 75,5 мг/кг [13]. При изучении содержания цинка в почвах пригородных лесов выявлено, что металл содержится в количестве 68,2 мг/кг. Средняя концентрация металла в городских парках - 83,2 мг/кг.

Свинец. Кларк свинца в почвах составляет 10 мг/кг. ПДК - 30 мг/кг [23]. Региональный фоновый уровень 11,2 мг/кг [13]. Свинец на исследуемых участках накапливается в количестве 1,9-23,1 мг/кг (пригородные леса) и 4-20,8 мг/кг сухой почвы (городские парки).

Кобальт. Кларк кобальта в почвах составляет 10 мг/кг. ПДК кобальта в почве составляет - 50 мг/кг [23]. Региональный фоновый уровень - 12,4 мг/кг [13]. В почвах металл отмечен только в Загородном парке. Его содержание в почве не превышает значений ПДК и регионального фонового уровня.

Титан. ПДК титана в почвах составляет 5000 мг/кг [23], региональный фоновый уровень для изучаемых типов почв - 4800 мг/кг [13]. Металл накапливается в почвах исследуемых участков в количестве 21173400,5 мг/кг (пригородные леса) и 1727,8-3299,4 мг/кг сухой почвы (городские парки). Содержание элемента не превышает значений регионального фонового уровня и ПДК.

Ванадий. ПДК ванадия в почвах составляет 150 мг/кг [23]. Региональный фоновый уровень - 77 мг/кг [13]. Установлено, что металл концентрируется в пределах 33,5-70,4 мг/кг (пригородные леса) и 40,7-71,4 мг/кг (городские парки) сухой почвы, что ниже значений ПДК и регионального фонового уровня.

Стронций. Кларк стронция в почвах составляет 200 мг/кг. ПДК не установлена. Региональный фоновый уровень - 171,9 мг/кг [13]. Содержание стронция в почвах исследуемых участков составляет от 86,9 мг/кг до 150,3 мг/кг и не превышает значений регионального фонового уровня.

Таким образом, основные элементы, которые присутствуют в техногенных потоках загрязнения - медь, никель, хром, цинк и свинец (табл. 1).

Наблюдается значительное превышение фоновых значений по меди и никелю. В меньшей степени загрязняют среду ванадий, стронций и титан. Наличие марганца, железа, никеля, цинка и свинца не превышает ПДК, но выше регионального фонового уровня. Превышение кларков железа и марганца связано с естественным их содержанием в почвах. Количество хрома незначительно превышает пороговые значения. Наиболее сильным загрязнителем является медь.

Таблица 1 - Содержание в почвах тяжёлых металлов, присутствующих в потоках загрязнения, мг/кг

\begin{tabular}{|c|c|c|c|c|}
\hline $\begin{array}{l}\text { Тяжёлые } \\
\text { металлы }\end{array}$ & $\begin{array}{c}\text { Содержание } \\
\text { элемента в } \\
\text { почвах, } \\
\text { мг/кг }\end{array}$ & $\begin{array}{l}\text { ПДК, } \\
\text { мг/кг }\end{array}$ & \begin{tabular}{|c|} 
Региональный \\
фоновый уро- \\
вень, мг/кг
\end{tabular} & $\begin{array}{c}\text { Превышение } \\
\text { значений } \\
\text { фонового } \\
\text { уровня }\end{array}$ \\
\hline $\mathrm{Cu}$ & 74,2 & 55 & 28 & 2,65 \\
\hline $\mathrm{Ni}$ & 48,9 & 85 & 28,6 & 1,71 \\
\hline $\mathrm{Cr}$ & 106,9 & 100 & 102 & 1,05 \\
\hline $\mathrm{Zn}$ & 75,7 & 100 & 75,5 & 1,00 \\
\hline $\mathrm{Pb}$ & 8,1 & 30 & 11,2 & 0,72 \\
\hline
\end{tabular}

Повышенное содержание тяжелых металлов в почвах исследуемых участков связано с загрязнением техногенными потоками. Выяснение территорий, являющихся основными источниками полиметаллического загрязнения, представляет собой важную проблему и требует более детального и глубокого изучения. Полученные материалы могут служить основой для дальнейшего мониторинга в связи с усилением техногенного воздействия.

Концентрация тяжёлых металлов на участках Куйбышевской железной дороги составила в мг/кг воздушно-сухой почвы: $\mathrm{Fe}=47354,6$ мг/кг; $\mathrm{Cu}=58,2$ мг/кг; $\mathrm{Mn}=683,6$ мг/кг; $\mathrm{Cr}=136,4$ мг/кг. Данные результаты говорят о превышении содержания данных тяжелых металлов в почвах, так как фоновое их значение для Самарской области составляет: $\mathrm{Fe}=32003,9$ мг/кг; $\mathrm{Cu}=$ 34,6 мг/кг; $\mathrm{Mn}=554,3$ мг/кг; $\mathrm{Cr}=122,2$ мг/кг. В связи с близким, а подчас и непосредственным расположением сельскохозяйственных земель к железнодорожному полотну особенно важно учитывать загрязнение почв тяжелыми металлами в отводах железных дорог.

Полученные данные позволяют построить элементный ряд накопления тяжёлых металлов по убыванию их концентраций в почвогрунтах исследуемых участков: $\mathrm{Fe}(25456,4 \mathrm{M \Gamma} / \kappa г)>\mathrm{Ti}(2623,6 \mathrm{Mг} /$ кг $)>\mathrm{Mn}$ $(692,6 \mathrm{Mг} / \kappa г)>\mathrm{Sr}(127,9$ мг/кг) $>\mathrm{Cr}(105,9$ мг/кг $)>\mathrm{Zn}$ $(73,2$ мг/кг) $>\mathrm{Cu}(73,9$ мг/кг) $>\mathrm{V}(51,8$ мг/кг $)>\mathrm{Ni}(48,3$ $\mathrm{Mг} / \mathrm{\kappa})>\mathrm{Pb}(8,8 \mathrm{мг} / \kappa \Gamma)$.

На всех исследуемых территориях наблюдается превышение фоновых значений по большинству выявленных тяжёлых металлов, за исключением титана, ванадия и стронция. Основными элементами, которые присутствуют в техногенных потоках загрязнения почв г. Самары и его окрестностей являются свинец, цинк, хром, никель и медь.

\section{СПИСОК ЛИТЕРАТУРЫ:}

1. Казанцев И.В. Экологическая оценка влияния железнодорожного транспорта на содержание тяжёлых металлов в почвах и растениях полосы отвода: автореф. дис. ... канд. биол. наук. Тольятти, 2008. 20 с.

2. Крошечкина И.Ю. Комплексная оценка загрязнений почвы полосы отвода железнодорожного транспорта и рекомендации по ее восстановлению: автореф. дис. ... канд. тех. наук. М., 2013. 24 с.

3. Сахарова А.С. Минимизация негативного воздействия ионов тяжелых металлов на объектах железнодорожного транспорта: автореф. дис. ... канд. тех. наук. M., 2013. 24 c. 
4. Стрелков А.К., Саргсян А.М. Исследование поверхностного стока с технической полосы отвода железнодорожных путей на наличие загрязнений // Tрадиции и инновации в строительстве и архитектуре. Строительные технологии: сборник статей. под ред. М.И. Бальзанникова， К.С. Галицкова， А.К. Стрелкова; Самарский государственный архитектурно-строительный университет. Самара, 2015. С. 236-240.

5. Теплых С.Ю., Бухман Н.С., Саргсян А.М. Исследование полосы отвода железнодорожных путей на наличие загрязнений // Научное обозрение. 2014. № 93. C. $802-808$.

6. Журавлева М.А., З Зубрев Н.И., Кокин С.М. Загрязнение полосы отвода // Мир транспорта. 2012. T. 10. № 3 (41). C. 112-118.

7. Zhuravleva M.A., Zubrev N.I., Kokin S.M. Contamination of roadside areas with heavy metals //Мир транспорта. 2014. Т. 12. № 6 (55). С. 174-181.

8. Тихонова Л.В., Тельминова О.В., Ларионова А.П. Накопление некоторых тяжелых металлов в почвах и растениях вблизи железной дороги // Вестник Курганского государственного университета. Серия: Естественные науки. 2006. № 8. С. 106-108.

9. Прохорова Н.В., Матвеев Н.М. Тяжелые металлы в почвах и растениях в условиях техногенеза // Вестник СамГУ. 1996. № 2. С. 125-144.

10. Канищев А.Н. Снижение негативного воздействия автомобильного транспорта за счет оптимального расположения лесных полос // Научный вестник Воронежского государственного архитектурно-строительного университета. Строительство и архитектура. 2014. № 2 (34). C. 71-76.

11. Копылова Л.В. Накопление тяжелых металлов в древесных растениях на урбанизированных территориях Восточного Забайкалья: автореф. дис. ... канд. биол. наук. Улан-Удэ, 2012. 24 c.

12. Казанцев И.В., Матвеева Т.Б., Молчатский С.Л. Содержание тяжёлых металлов в почвенном покрове пригородных лесов города Самары // Карельский научный журнал. 2015. № 4 (13). С. 83-86.

13. Прохорова Н.В., Матвеев Н.М. Территориальные особенности распределения тяжёлых металлов в почвах Самарской области // Известия Самарского научного центра РАН. 2000. Т. 2. № 2. С. 306-310.

14. Прохорова Н.В. Оценка полиметаллического загрязнения почвенного покрова Самарской Луки // Известия Самарского научного центра РАН. 2003. Вып. 2. T. 5 C. 295-304.

15. Гнеденко В.В., Обущенко С.В. Современное состояние и тенденции изменения содержания тяжёлых металлов в почвах Самарской области // Международный журнал прикладных и фундаментальных исследований. 2011. № 10. С. 42-44.

16. Обущенко С.В., Гнеденко В.В. Мониторинг содержания микроэлементов и тяжёлых металлов в почвах Самарской области // Международный журнал прикладных и фундаментальных исследований. 2014. № 7. С. 30-34.

17. Медведева М.В., Титова Т.С., Федорец Н.Г., Пеккоев А.Н. Экологическая оценка влияния железнодорожного транспорта на свойства почв и прирост соснового древостоя // Экология и промышленность России. 2016. № 1. С. 48-53.

18. Медведева М.В., Федорец Н.Г., Яковлев А.С., Савельев Л.Л. Экологическая оценка почв техногенных зон урбанизированных территорий // Транспорт Российской Федерации. 2014. № 1 (50). С. 54-57.

19. Методические рекомендации по проведению полевых и лабораторных исследований почв и растений при контроле загрязнения окружающей среды металлами / под ред. Н.Г. Зырина, С.Г. Малахова. М.: Изд-во «Гидрометеоиздат», 1981. 109 с.

20. Алексеенко В.В. Геохимия ландшафта и окружающая среда. М.: Изд-во «Наука», 1990. 142 с.

21. Гончарук Е.И. Гигиеническое нормирование химических веществ в почве. М.: Изд-во «Медицина», $1986.320 \mathrm{c}$

22. Майстренко В.Н., Х Хамитов Р.3., Будников Г.К. Эколого-аналитический мониторинг супертоксикантов. М.: Изд-во «Химия», 1996. 312 с.

23. Перечень предельно-допустимых концентраций (ПДК) и ориентировочно-допустимых количеств (ОДК) химических веществ в почве. Издание специальное. М.: Изд-во Госкомсанэпиднадзора России, 1991. 18 с.

\section{CONTENTS OF HEAVY METALS IN THE SOIL COVER IN THE CONDITIONS OF TECHNOGENESIS}

(C) 2016

I.V. Kazantsev, candidate of biological sciences, dean of the Faculty of Natural Sciences and Geography

T.B. Matveyeva, candidate of biological sciences, senior lecturer

of the Chair of Biology, Ecology and Methods of Teaching

Samara State University of Social Sciences and Education, Samara (Russia)

Abstract. The paper examines pollution of soils with heavy metals under technogenic impact. The ways and means of pollutants receipt in soils and their accumulation in soils located in the drainage of railway are described. The role of roadside forest belts on the distribution of pollutants is examined. Determination of heavy metals content in soils was carried out by the x-ray fluorescence method. The results of heavy metal soil pollution in comparison with Clarke value, maximum permissible concentration and regional background levels are represented. The study of heavy metals content was carried out in the soils of right-of-way on the Samara-Syzran section of the Kuibyshev railway, as well as in suburban forests and urban parks of Samara (Botanical garden, Country Park). These areas are exposed to significant anthropogenic impact. Studies have shown that in these areas an increased content of some heavy metals in soils is observed. The main elements present in anthropogenic flows of pollution are copper, nickel, chromium, zinc and lead. This result does not contradict the standard environmental situation. These materials can serve as a basis for further monitoring of suburban forests of Samara green zone and transport facilities.

Keywords: heavy metals, pollutants, element number accumulation, maximum permissible concentration, regional background levels, the suburban forests, forest belt, environmental monitoring, soil monitoring, Railways, Kuybyshev railway, Samara city, Samara Region. 